\title{
Vitamin D, parathyroid hormone and metabolic syndrome - the PORMETS study
}

Luís Raposo ${ }^{1,2^{*}}$ D, Sandra Martins ${ }^{2,3}$, Daniela Ferreira ${ }^{2}$, João Tiago Guimarães ${ }^{2,3,4}$ and Ana Cristina Santos ${ }^{1,2,5}$

\begin{abstract}
Background: Vitamin D (VitD) and parathyroid hormone (PTH) play important roles in calcium metabolism and skeletal homeostasis. Estimates of the VitD status in several European countries show large variations between them. In addition, no national population-based estimate has been published. VitD and PTH may also play important roles in cardiovascular risk, which has been suggested to be associated with metabolic syndrome (MetS) and is very prevalent in Portugal.

The goal of our study was to evaluate the prevalence of hypovitaminosis D and its determinants as well as PTH serum level determinants and associations of the 25-hydroxyvitamin D and PTH serum levels with MetS and its individual components in a sample of the Portuguese mainland population.

Methods: PORMETS is a national cross-sectional study that includes a total sample of 4095 adults. A subsample, including 500 participants, was randomly selected for the present study. A structured questionnaire was administered to collect information on personal medical histories and socio-demographic and behavioral characteristics. Blood pressure and anthropometrics measurements were performed. Fasting venous samples were collected and PTH and 25hydroxyvitamin D were measured. VitD adequacy was classified according to the Institute of Medicine, and MetS was classified according to the Joint Interim Statement recommendations. Multiple linear regression and unconditional logistic regression models were used to estimate the associations between the levels of PTH and 25-hydroxyvitamin D and with MetS and its individual components.
\end{abstract}

Results: The prevalence of VitD deficiency was 37.7\%, and MetS was present in 191 participants (38.4\%). The serum PTH levels showed a positive association (OR: 1.014; 95\%Cl: 1.002, 1.026) with the waist circumference component of MetS. The serum 25-hydroxyvitamin D levels were negatively associated with MetS (OR: 0.957; 95\%Cl: $0.922,0.993)$ as well as with its blood pressure (OR: 0.949; 95\% Cl: $0.912,0.987)$ and triglycerides (OR: 0. 930; 95\% Cl: 0.892, 0.969) components.

Conclusion: This study showed a high national prevalence of hypovitaminosis D. The PTH levels showed a significant positive association with the WC component of MetS, and the VitD levels were negatively associated with the $\mathrm{BP}$ and triglycerides components as well as with the MetS.

Keywords: Vitamin D, PTH, Functional hypoparathyroidism, Metabolic syndrome, Cardiovascular risk, Prevalence, Portugal

\section{Background}

Vitamin D (VitD) is a fat-soluble vitamin that is involved in the metabolism of calcium and skeletal homeostasis [1]. Cholecalciferol (VitD3), the main source of VitD, is synthesized in the skin from the cholesterol precursor

\footnotetext{
* Correspondence: luisraposoendo@gmail.com

'Grupo de Estudo da Insulino-Resistência, Sociedade Portuguesa de Endocrinologia, Diabetes e Metabolismo, Lisboa, Portugal

2EPIUnit - Instituto de Saúde Pública da Universidade do Porto (ISPUP), Porto, Portugal

Full list of author information is available at the end of the article
}

7-dehydrocholesterol through exposure to ultraviolet (UV) B radiation. VitD from dietary sources and sun exposure is not biologically active and must undergo two hydroxylations in the human body for activation. VitD is first hydroxylated by the liver to form 25-hydroxyvitamin D [25(OH)D], also known as calcidiol, which is then primarily hydroxylated by the kidney to form the physiologically active $1 \alpha, 25(\mathrm{OH})_{2} \mathrm{D}$, or calcitriol. Calcidiol has low bioactivity but is the main form of VitD in the blood stream and best indicator of VitD status. 
According to a recent review [2], estimates of the VitD status in several European countries showed large variations. No national population-based study has been published, and the only available Portuguese studies involved regional or specific groups using hospital-based recruitment. According to a recent study in Portuguese hospitalized patients, VitD deficiency or inadequacy was present in $60.3 \%$ of these patients [3].

An inadequate VitD status may play a significant role in cardiovascular disease (CVD) risk [4], and several observational studies suggest an association between hypovitaminosis D and metabolic syndrome (MetS), which represents a cluster of interrelated risk factors for CVD [5]. In addition, MetS is highly prevalent in Portugal. [6] An evaluation of the potential associations of MetS and its individual components with VitD levels may support and enhance current knowledge of the effects of VitD on CVD risk factors.

Parathyroid hormone (PTH), a hormone with a close regulatory relationship with VitD, has also been associated with CVD events [7]. Findings from populationbased cross-sectional studies have suggested a positive association between PTH and MetS among older men [8] and in morbidly obese individuals [9]. The goal of our study was to evaluate the prevalence of hypovitaminosis D and its determinants as well as PTH serum levels determinants and associations of the 25(OH)D and PTH serum levels with MetS and its individual components in a sample of the Portuguese mainland population.

\section{Methods}

PORMETS (PORtuguese METabolic Syndrome) is a national cross-sectional study that includes a sample of adults registered in primary health care centers of the Portuguese mainland. Information regarding PORMETS recruitment proceedings and methodology have been previously published by the authors [10]. According to national legislation, all citizens are enrolled in the health center of their zone of residence. In each of the eighteen Portuguese mainland administrative regions (districts), two health care centers were included. One was in the district's capital and the other represented a non-urban area. In each center, participants were randomly selected from the general practitioners' lists, and 120 participants were evaluated under an inclusion criterion of 18 years of age or older. The selected participants went to the health center specifically to participate in the study. A total of 4105 participants were evaluated, and information was collected from February 2007 to July 2009. Ten participants were excluded from data analysis because they were pregnant at the time of the interview. Therefore, 4095 participants remained.
For this particular study, 500 participants (286 women and 214 men) were randomly selected from the initial PORMETS sample. This sub-sample size was calculated considering a margin of error of $5 \%$, confidence level of 95\% and response distribution of 50\% for the proportion of participants with $25(\mathrm{OH}) \mathrm{D}$ levels below $30 \mathrm{ng} / \mathrm{mL}$ $(75 \mathrm{nmol} / \mathrm{L})$. The comparison between the selected and unselected participants did not show significant differences, except for systolic blood pressure and for insulin serum levels (Table 1). The PORMETS study was approved by the Portuguese Regional Health Administrations, the Ethics Committee of the São João Hospital E.P.E. and the Portuguese Data Protection Authority. Additionally, approval from each Clinical Director of the health care centers was received, and all participants provided written informed consent.

A structured questionnaire was administered to collect information on personal medical histories and sociodemographic and behavioral characteristics. The participants were considered current smokers if they smoked daily or occasionally, former smokers if they had stopped smoking for at least 6 months, and non-smokers if they had never smoked. Regarding alcohol intake, participants were categorized as occasional drinkers if they had less than one drink per day, daily drinkers if they consumed at least one drink per day, former drinkers if had stopped drinking for at least 6 months and non-drinkers if they had never consumed any type of alcoholic beverage. Regular physical exercise was considered when the participant was engaged in some leisure time physical activity on a repeated basis for at least $30 \mathrm{~min}$ a week. Participants who were evaluated in the JuneNovember period and December-May period were classified, respectively, as "higher" and "lower" UV radiation exposure.

Anthropometrics measurements were performed, including weight, height (Ht) and waist (WC) and hip $(\mathrm{HC})$ circumferences. Weight was measured to the nearest $0.1 \mathrm{~kg}$ using a digital scale, and $\mathrm{Ht}$ was measured to the nearest centimeter in the standing position using a wall stadiometer. WC was measured midway between the bottom of the rib cage and iliac crest, and $\mathrm{HC}$ was measured as the maximum circumference of the buttocks. The waist-to-height ratio (WHtR) was calculated as the WC divided by the Ht, and the waist-to-hip ratio (WHR) was calculated as the WC divided by the HC. Body mass index (BMI) was calculated as weight in kilograms divided by the square of $\mathrm{Ht}$ in meters, and participants were classified according to the World Health Organization criteria [11]: underweight, normal range, pre-obese and obese categories, which are defined as BMI < $18.5 \mathrm{~kg} / \mathrm{m}^{2}, \geq 18.5$ to $<25 \mathrm{~kg} / \mathrm{m}^{2}, \geq 25$ to $<30 \mathrm{~kg} / \mathrm{m}^{2}$ and $\geq 30 \mathrm{~kg} / \mathrm{m}^{2}$, respectively. 
Table 1 Comparison between selected and unselected participants

\begin{tabular}{|c|c|c|c|}
\hline Variables & Unselected participants & Selected participants & $p$ value \\
\hline \multicolumn{4}{|l|}{ Gender ( $\mathrm{n})$} \\
\hline Women & 2069 & 286 & \\
\hline Men & 1526 & 214 & 0.881 \\
\hline Age - years [median (P25, P75)] & $54(41,66)$ & $53(41,67)$ & 0.856 \\
\hline Education level - years [median (P25, P75)] & $4(4,10)$ & $6(4,10)$ & 0.252 \\
\hline \multicolumn{4}{|l|}{ Alcohol intake (n) } \\
\hline Non-drinker & 1618 & 229 & \\
\hline Former drinker & 124 & 18 & \\
\hline Occasional drinker & 934 & 128 & \\
\hline Daily drinker & 892 & 123 & 0.990 \\
\hline \multicolumn{4}{|l|}{ Smoking habits (n) } \\
\hline Non-smoker & 2486 & 358 & \\
\hline Former smoker & 521 & 66 & \\
\hline Smoker & 529 & 70 & 0.597 \\
\hline \multicolumn{4}{|l|}{ Physical exercise (n) } \\
\hline No & 2592 & 352 & \\
\hline Yes & 954 & 139 & 0.597 \\
\hline \multicolumn{4}{|l|}{ UV exposure (n) } \\
\hline Lower & 1971 & 283 & \\
\hline Higher & 1555 & 217 & 0.768 \\
\hline Weight - cm [median (P25, P75)] & $71.0(62.5,80.5)$ & $71.0(61.0,80.0)$ & 0.704 \\
\hline Height - cm [median (P25, P75)] & $162.0(155.5,169.0)$ & $162.0(155.0,169.0)$ & 0.745 \\
\hline $\mathrm{BMI}-\mathrm{Kg} / \mathrm{m}^{2}$ [median (P25, P75)] & $27.0(24.0,30.0)$ & $27.1(24.1,29.8)$ & 0.813 \\
\hline WC - cm [median (P25, P75)] & $93.4(85.0,101.5)$ & $93.5(86.0,102.0)$ & 0.399 \\
\hline Systolic BP - mmHg [median (P25, P75)] & $130(116,145)$ & $131(119,147)$ & 0.038 \\
\hline Diastolic BP - mmHg [median (P25, P75)] & $79(70,86)$ & $80.0(70,87)$ & 0.073 \\
\hline Glucose - mg/dL [median (P25, P75)] & $85(77,97)$ & $85(77,97)$ & 0.947 \\
\hline Insulin - $\mu \mathrm{U} / \mathrm{mL}$ [median (P25, P75)] & $7.6(5.1,11.4)$ & $8.0(5.3,12.2)$ & 0.040 \\
\hline HOMA - median (P25, P75) & $1.6(1.0,2.6)$ & $1.7(1.1,2.9)$ & 0.119 \\
\hline hs-CRP - mg/L [median (P25, P75)] & $0.15(0.07,0.36)$ & $0.16(0.08,0.39)$ & 0.626 \\
\hline Cholesterol - mg/dL [median (P25, P75)] & $206(179,233)$ & $204(180,233)$ & 0.611 \\
\hline Triglycerides - mg/dL [median (P25, P75)] & $106(78,147)$ & $104(76,143)$ & 0.242 \\
\hline HDL-cholesterol - mg/dL [median (P25, P75)] & $47(39,55)$ & $47(39,55)$ & 0.553 \\
\hline \multicolumn{4}{|l|}{ MetS (n) } \\
\hline No & 2086 & 307 & \\
\hline Yes & 1403 & 191 & 0.428 \\
\hline \multicolumn{4}{|l|}{ BP component (n) } \\
\hline No & 1352 & 177 & \\
\hline Yes & 2172 & 322 & 0.212 \\
\hline \multicolumn{4}{|l|}{ WC component (n) } \\
\hline No & 1812 & 253 & \\
\hline Yes & 1702 & 247 & 0.686 \\
\hline
\end{tabular}


Table 1 Comparison between selected and unselected participants (Continued)

\begin{tabular}{|c|c|c|c|}
\hline Variables & Unselected participants & Selected participants & $p$ value $^{\mathrm{a}}$ \\
\hline \multicolumn{4}{|c|}{ Glycemia component (n) } \\
\hline No & 2655 & 382 & \\
\hline Yes & 822 & 112 & 0.635 \\
\hline \multicolumn{4}{|c|}{ HDL-cholesterol component (n) } \\
\hline No & 1566 & 224 & \\
\hline Yes & 1935 & 276 & 0.977 \\
\hline \multicolumn{4}{|c|}{ Triglycerides component (n) } \\
\hline No & 2615 & 383 & \\
\hline Yes & 878 & 117 & 0.401 \\
\hline
\end{tabular}

Blood pressure (BP) was measured on a single occasion using a standard mercury sphygmomanometer with the cuff on the right upper arm after a 10-min rest. Two $\mathrm{BP}$ readings were taken and the mean of the two readings was calculated. If the difference between the two measurements was greater than $5 \mathrm{mmHg}$ for the systolic or the diastolic BP, a third measurement was taken and the mean of the two closest values was registered.

Fasting venous blood samples were collected by trained nurses in each health care center, and the samples were stored at $-80{ }^{\circ} \mathrm{C}$.

A chemiluminescent immunoassay using a Liaison automated analyzer (Diasorin Iberia, Madrid, Spain) was used to measure 25(OH)D. Biointact PTH and insulin were determined by an electro-chemiluminescent immunoassay using a Cobas e411 automated analyzer (Roche, Amadora, Lisboa, Portugal). High sensitivity Creactive protein (hs-CRP) was measured using a particleenhanced immunonephelometric assay on a BN II laser nephelometer. (Siemens Healthcare, Amadora, Lisboa, Portugal). All other parameters (glucose, total cholesterol, triglycerides, HDL-cholesterol, calcium, phosphorus, albumin and creatinine) were measured using conventional methods with an Olympus AU5400 automated clinical chemistry analyzer. (Beckman-Coulter,Oeiras, Lisboa, Portugal). Insulin resistance was estimated by the Homeostatic Model Assessment (HOMA), from fasting glucose $(\mathrm{mmol} / \mathrm{L})$ and insulin $(\mu \mathrm{UI} / \mathrm{mL})$, as the product of the two divided by 22.5 .

VitD adequacy was classified according to the Institute of Medicine (IOM) recommended cut-off values for 25(OH)D levels [12]: deficiency below $12 \mathrm{ng} / \mathrm{mL}$ (30 nmol/L); inadequacy $\geq 12$ and $<20 \mathrm{ng} / \mathrm{mL}$ ( $\geq 30$ and $<50 \mathrm{nmol} / \mathrm{L})$ and sufficiency $\geq 20 \mathrm{ng} / \mathrm{mL}(\geq 50 \mathrm{nmol} / \mathrm{L})$. Hyper- and hypoparathyroidism were defined as PTH levels above and below the standard laboratory reference range $(10-65 \mathrm{pg} / \mathrm{mL})$, respectively, and a "blunted PTH response" was defined as a PTH level within the reference range in the presence of $25(\mathrm{OH}) \mathrm{D} \leq 12 \mathrm{ng} / \mathrm{mL}$ (30 nmol/L) [13].

MetS was defined according to the Joint Interim Statement [14] and was considered to be present if at least three (any) of the following characteristics were present: fasting glucose $\geq 100 \mathrm{mg} / \mathrm{dL}$ or drug treatment for elevated glucose; systolic $\mathrm{BP} \geq 130$ and/or diastolic $\mathrm{BP} \geq$ $85 \mathrm{mmHg}$ or antihypertensive drug treatment in a patient with a history of hypertension; triglycerides $\geq 150 \mathrm{mg} / \mathrm{dL}(1.7 \mathrm{mmol} / \mathrm{L})$ or drug treatment for elevated triglycerides; HDL cholesterol $<50 \mathrm{mg} / \mathrm{dL}(1.3 \mathrm{mmol} / \mathrm{L})$ in women and $<40 \mathrm{mg} / \mathrm{dL}(1.0 \mathrm{mmol} / \mathrm{L})$ in men or drug treatment for reduced HDL-cholesterol; WC $\geq 88 \mathrm{~cm}$ in women and $\geq 102 \mathrm{~cm}$ in men ("European" criteria).

Statistical analysis: Quantitative data are described as the median values and corresponding 25th (P25) and 75th (P75) percentiles. Counts and proportions were reported for categorical variables. Proportions were compared using the chi-square test or Fisher's exact test when appropriate. Mann-Whitney $U$ test was used to compare differences between two independent groups. Multiple linear regression models, with the PTH and 25(OH) D levels as dependent variables, were used to calculate the regression coefficients and their respective 95\% confidence intervals (95\%CI) of several independent variables, including gender, age, level of education, drinking and smoking habits, UV radiation exposure, physical exercise, $\mathrm{Ht}$, weight, BMI, WC, HC, WHR, WHtR, systolic and diastolic BP, glucose, triglycerides, HDL-cholesterol, total cholesterol, insulin, HOMA, hs-CRP, albumin, calcium, phosphorus and creatinine. The final model was adjusted for age and sex. Unconditional logistic regression models with MetS, its individual components or a "blunted PTH response" as dependent variables were computed, and the odds ratios (OR) and their respective 95\% CI were estimated after adjustments for confounding variables. 
Results with a two-tailed $p$ value $<0.05$ were considered statistically significant. Statistical analysis was performed using SPSS version $22^{\circ}$ software.

\section{Results}

A total of 500 participants (286 women and 214 men) with a median age (P25, P75)) of $53(41,67)$ years $[52(40,66)$ years in women and $56(45,68)$ years in men] were included in the present analysis.

The sample characteristics of the 500 participants are presented in Table 2. The median 25(OH)D level was $13.8 \mathrm{ng} / \mathrm{mL}$, with a maximum value of $43.5 \mathrm{ng} /$ $\mathrm{mL}$. According to the VitD adequacy categories, deficiency was present in $37.7 \%$ of participants, inadequacy was identified in $47.9 \%$ of participants and sufficiency was determined in $14.4 \%$ of participants. A seasonal variation of serum $25(\mathrm{OH}) \mathrm{D}$ was observed, with significantly higher median values in June-November period compared to the December-May period ( $p$ 0.001). The median serum PTH level was $38.1 \mathrm{pg} / \mathrm{mL}$, and hypo- and hyperparathyroidism were present in $0.8 \%$ and $9.4 \%$ of the participants, respectively.

A "blunted PTH response" was present in $89.2 \%$ of the 185 participants, with serum 25(OH)D levels of less than or equal to $12 \mathrm{ng} / \mathrm{mL}$ (Table 3). A "blunted PTH response" was more frequent in men (OR: 4.100; 95\%CI: $1.289,13.036)$, and the frequency decreased with age (OR: 0.960; 95\%CI: 0.930, 0.992). Furthermore, participants with a "blunted PTH response" had significantly higher serum phosphorus levels (OR: 4.590; 95\%CI: 1.425, 14.781) and lower hs-CRP levels (OR: 0.493; 95\%CI: $0.258,0.943$ ).

The associations of the PTH and 25(OH)D levels with various socio-demographic, behavioral and clinical characteristics are presented in Table 4.

The serum levels of PTH and 25(OH)D showed no significant association between them $(p=0.770)$.

Table 2 Sample characteristics of the 500 participants

\begin{tabular}{|c|c|c|c|c|}
\hline & Total & Women & Men & $p$ value \\
\hline Age (years) - median (P25, P75) & $53(41,67)$ & $52(40,66)$ & $56(45,68)$ & 0.072 \\
\hline 25(OH)D (ng/mL) - median (P25, P75) & $13.8(9.7,17.6)$ & $13.8(9.7,17.5)$ & $13.7(9.9,17.9)$ & 0.681 \\
\hline \multicolumn{5}{|c|}{$25(\mathrm{OH}) \mathrm{D}(\mathrm{ng} / \mathrm{mL}) / \mathrm{UV}$ exposure - median (P25, P75) } \\
\hline Low UV & $13.4(9.3,17.5)$ & $13.4(9.3,16.6)$ & $13.2(9.0,17.9)$ & \\
\hline High UV & $14.3(10.0,18.3)^{b}$ & $14.1(9.9,18.6)$ & $14.5(10.2,17.6)$ & 0.603 \\
\hline \multicolumn{5}{|l|}{ VitD adequacy - n (\%) } \\
\hline Deficiency & $181(37.7)$ & $102(37.5)$ & $79(38.0)$ & \\
\hline Inadequacy & $230(47.9)$ & $133(48.9)$ & $97(46.6)$ & \\
\hline Sufficiency & $69(14.4)$ & 37 (13.6) & $32(15.4)$ & 0.821 \\
\hline PTH (pg/mL) - median (P25, P75) & $38.1(29.8,49.2)$ & $38.6(29.8,50.1)$ & $37.8(30.0,47.7)$ & 0.375 \\
\hline \multicolumn{5}{|l|}{ "Blunted PTH response" - n (\%) } \\
\hline No & $20(10.8)$ & $16(15.4)$ & $4(4.9)$ & \\
\hline Yes & $165(89.2)$ & $88(84.6)$ & $77(95.1)$ & 0.023 \\
\hline \multicolumn{5}{|l|}{ PTH status - n (\%) } \\
\hline Hypoparathyroidism & $4(0.8)$ & $0(0)$ & $4(1.9)$ & \\
\hline Normal status & 449 (89.8) & $254(88.8)$ & $195(91.1)$ & \\
\hline Hyperparathyroidism & $47(9.4)$ & $32(11.2)$ & $15(7.0)$ & 0.021 \\
\hline \multicolumn{5}{|l|}{ BMI classification - n (\%) } \\
\hline Underweight & $6(1.2)$ & $5(1.7)$ & $1(0.5)$ & \\
\hline Normal range & 159 (31.9) & $94(32.9)$ & $65(30.5)$ & \\
\hline Pre-obese & $213(42.7)$ & $113(39.5)$ & $100(46.9)$ & \\
\hline Obese & $121(24.2)$ & $74(25.9)$ & $47(22.1)$ & 0.242 \\
\hline \multicolumn{5}{|l|}{ Metabolic syndrome - n (\%) } \\
\hline No & 307 (61.6) & $169(59.3)$ & $138(64.8)$ & \\
\hline Yes & $191(38.4)$ & $116(40.7)$ & 75 (35.2) & 0.213 \\
\hline
\end{tabular}

SD standard deviation, 25(OH)D 25-hydroxyvitamin D, VitD vitamin D, UV ultraviolet, low UV period December-May, high UV period June-November, PTH parathyroid hormone, $B M I$ body mass index

${ }^{a}$ Chi-square test/Fisher's exact test or Mann-Whitney $U$ test $\mathrm{p}$ value; ${ }^{\mathrm{b}} p$ value $<0.001$ for the comparison of the mean levels of $25(\mathrm{OH}) \mathrm{D}$ according to meteorological periods 
Table 3 "Blunted PTH response" characteristics

\begin{tabular}{lll}
\hline & Crude OR $(95 \% \mathrm{Cl})$ & OR $(95 \% \mathrm{Cl})^{\mathrm{a}}$ \\
\hline \begin{tabular}{l} 
Gender \\
\multicolumn{1}{c}{ Women } \\
\multicolumn{1}{c}{ Men }
\end{tabular} & \\
Age & $3.500(1.122,10.917)$ & $4.100(1.289,13.036)$ \\
Height & $0.964(0.933,0.996)$ & $0.960(0.930,0.992)$ \\
BMI & $1.064(1.006,11.125)$ & $1.002(0.925,1.085)$ \\
Systolic BP & $0.936(0.868,1.010)$ & $0.960(0.889,1.037)$ \\
Calcium & $0.981(0.962,1.000)$ & $0.982(0.958,1.006)$ \\
Phosphorus & $1.138(0.223,5.825)$ & $1.077(0.211,5.486)$ \\
Albumin & $3.179(1.173,8.615)$ & $4.590(1.425,14.781)$ \\
Insulin & $1.186(1.050,1.341)$ & $1.138(0.998,1.299)$ \\
HOMA & $0.970(0.909,1.036)$ & $0.969(0.906,1.036)$ \\
hs-CRP & $1.003(0.979,1027)$ & $1.003(0.964,1.044)$ \\
\hline Some f the vaiabs $)$ & $0.493(0.258,0.943)$ \\
\hline
\end{tabular}

Some of the variables without significant associations were excluded from the table: education level, drinking and smoking habits, physical exercise, UV exposure, weight, hip and waist circumferences, WHR, WHtR, diastolic BP, glucose, triglycerides, $\mathrm{HDL}$-cholesterol, total cholesterol, creatinine, and 25(OH)D $O R$ odds ratio, $C l$ confidence interval, $B M I$ body mass index, $B P$ blood pressure, HOMA homeostatic model assessment, $h s-C R P$ high sensitivity C-reactive protein ${ }^{\mathrm{a} O R}$ adjusted for gender and age

Table 4 Associations of PTH and 25(OH)D with socio-demographic, anthropometric, clinical and analytical characteristics

\begin{tabular}{|c|c|c|c|c|}
\hline & \multicolumn{2}{|l|}{ PTH } & \multicolumn{2}{|l|}{$25(\mathrm{OH}) \mathrm{D}$} \\
\hline & $\beta(95 \% \mathrm{Cl})^{\mathrm{b}}$ & $p$ value & $\beta(95 \% \mathrm{Cl})^{\mathrm{b}}$ & $p$ value \\
\hline \multicolumn{5}{|l|}{ Gender } \\
\hline Women & a & & a & \\
\hline Men & $-3.331(-6.415,-0.246)$ & 0.034 & $0.383(-0.666,1.433)$ & 0.473 \\
\hline Age (years) & $0.320(0.225,0.415)$ & $<0.001$ & $-0.029(-0.061,0.003)$ & 0.080 \\
\hline \multicolumn{5}{|l|}{ UV exposure } \\
\hline Low UV & a & & a & \\
\hline High UV & $-0.531(-2.541,3.603)$ & 0.734 & $0.940(-0.105,1.985)$ & 0.078 \\
\hline \multicolumn{5}{|l|}{ Physical exercise } \\
\hline No & a & & a & \\
\hline Yes & $-2.346(-5.799,1.087)$ & 0.180 & $1.655(0.484,2.826)$ & 0.006 \\
\hline BMI & $0.475(0.143,0.807)$ & 0.005 & $-0.150(-0.262,-0.037)$ & 0.009 \\
\hline WC & $0.184(0.048,0.320)$ & 0.008 & $-0.039(-0.085,0.008)$ & 0.101 \\
\hline Glucose & $-2.319(-7.704,3.066)$ & 0.398 & $-2.051(-3.903,-0.199)$ & 0.030 \\
\hline Triglycerides & $-1.118(-3.557,1.322)$ & 0.368 & $-1.322(-2.139,-0.505)$ & 0.002 \\
\hline Calcium & $-2.098(-7.923,3.727)$ & 0.479 & $0.298(-1.690,2.286)$ & 0.768 \\
\hline Phosphorus & $-4.689(-7.567,-1.812)$ & 0.001 & $0.245(-0.748,1.238)$ & 0.628 \\
\hline Creatinine & $14.553(5.267,23.838)$ & 0.002 & $2.367(-0.789,5.522)$ & 0.141 \\
\hline PTH & & & $-0.004(-0.034,0.025)$ & 0.770 \\
\hline $25(\mathrm{OH}) \mathrm{D}$ & $-0.040(-0.311,0.230)$ & 0.770 & & \\
\hline
\end{tabular}

Some of the variables without significant associations were excluded from the table: level of education, drinking and smoking habits, height, weight, hip circumference, WHR, WHtR, systolic and diastolic BP, HDL-cholesterol, total cholesterol, albumin, insulin, HOMA and hs-CRP

Cl confidence interval, UV Ultraviolet, low UV period December-May, high UV period June-November, IMC body mass index, WC waist circumference, PTH parathyroid hormone serum levels, 25(OH)D 25-hydroxyvitamin D serum levels ${ }^{\text {a }}$ Reference class

${ }^{\mathrm{b}} \beta$ coefficients adjusted for gender and age
The serum PTH levels were significantly lower in men ( $\beta$ : $-3.331 ; 95 \% \mathrm{CI}:-6.415,-0.246)$ and were positively associated with age ( $\beta$ : $0.320 ; 95 \% \mathrm{CI}: 0.225,0.415)$. In addition, positive associations between PTH and BMI ( $\beta$ : 0.475 ; $95 \%$ CI: $0.143,0.807)$, WC ( $\beta: 0.184 ; 95 \% \mathrm{CI}: 0.048$, 0.320 ) and creatinine levels ( $\beta$ : 14.553; 95\%CI: 5.267, 23.838) were found. Furthermore, a negative association between PTH and serum phosphorus levels ( $\beta$ : -4.689 ; $95 \%$ CI: $-7.567,-1.812$ ) was observed.

The serum $25(\mathrm{OH}) \mathrm{D}$ levels were positively associated with participation in physical exercise $(\beta: 1.655 ; 95 \% \mathrm{CI}$ : $0.484,2.826)$ and were negatively associated with BMI ( $\beta$ : -0.150 ; 95\%CI: $-2.262,-0.037)$ and serum glucose $(\beta$ : $-2.051 ; 95 \% \mathrm{CI}:-3.903,-0.199)$ and triglycerides $(\beta$ : -1.322 ; 95\%CI: $-2.139,-0.505)$ levels.

MetS was present in 191 participants (38.4\%), and its prevalence was slightly higher in women than in men, but without statistical significance $(40.7 \%$ versus $35,2 \%$, $p=0.213)$. The MetS prevalence significantly increased with age $(p<0.001)$ and with higher HOMA scores $(p<$ $0.001)$ as well as higher insulin $(p<0.001)$ and hs-CRP $(p=0.027)$ levels.

Table 5 shows the associations of PTH and 25(OH)D with MetS and its individual components. The PTH serum levels showed a crude positive association with MetS (OR: 1.016; 95\%CI: 1.006, 1.027) and its WC (OR: 1.023; 95\%CI: 1.012, 1.034) and BP (OR: 1.022 ; 95\%CI: $1.010,1.034)$ features. After adjustments for age and sex (model 1), only the association with the WC feature remained significant. This association remained significant even after further adjustment for 25(OH)D levels (OR: 1.013; 95\%CI: 1.001, 1.015). After adjustment for age, sex and BMI (model 2), this association lost statistical significance.

We also found a crude negative association between the serum $25(\mathrm{OH})$ D levels and MetS (OR: 0.953; 95\%CI: 0.921, 0.985) and its BP (OR: 0.951; 95\%CI: 0.920, 0.983) and triglycerides (OR: 0.930; 95\%CI: 0.893, 0.969) components. After adjustments for age and sex (model 1), all the three associations remained significant. However, after further adjustment for BMI (model 2), the association remained statistically significant only for the BP and triglycerides components of the MetS [(OR: 0.954; 95\%CI: $0.916,0.993$ ) and (OR: $0.937 ; 95 \% \mathrm{CI}$ : $0.898,0.978)$, respectively].

\section{Discussion VitD status}

We found a high prevalence of VitD deficiency or inadequacy $(85.6 \%)$ in this sample of the Portuguese population. The high prevalence is supported by previously published national evidence (VitD deficiency or inadequacy ranging from $60.3 \%$ to $92.7 \%$ ), although specific population groups were recruited in hospital settings 
Table 5 Associations of PTH and $25(\mathrm{OH})$ D with MetS and its components

\begin{tabular}{llllll}
\hline & \multicolumn{1}{l}{ PTH } & & \multicolumn{2}{l}{ 25(OH)D } \\
\cline { 2 - 3 } \cline { 5 - 6 } & Model 1: OR $(95 \% \mathrm{Cl})$ & Model 2: OR $(95 \% \mathrm{Cl})$ & & Model 1: OR (95\% Cl) & Model 2: OR (95\% Cl) \\
\hline MetS & $1.004(0.993,1015)$ & $0.995(0.983,1.008)$ & $0.957(0.922,0.993)$ & $0.967(0.930,1.007)$ \\
WC & $1.014(1.002,1.026)^{\mathrm{a}}$ & $1.002(0.986,1.017)$ & $0.991(0.958,1.026)$ & $1.024(0.980,1.069)$ \\
BP & $1.006(0.992,1.020)$ & $1.001(0.988,1.016)$ & $0.949(0.912,0.987)$ & $0.954(0.916,0.993)$ \\
Trig & $0.996(0.983,1.008)$ & $0.991(0.978,1.004)$ & $0.930(0.892,0.969)$ & $0.937(0.898,0.978)$ \\
HDL & $0.998(0.988,1.009)$ & $0.995(0.985,1.006)$ & $0.990(0.959,1.023)$ & $0.997(0.965,1.030)$ \\
Glu & $0.998(0.985,1.010)$ & $0.994(0.981,1.007)$ & $0.975(0.936,1.016)$ & $0.990(0.949,1.033)$ \\
\hline
\end{tabular}

OR odds ratio, $\mathrm{Cl}$ confidence interval, $P T H$ parathyroid hormone serum levels, 25(OH)D 25-hydroxyvitamin D serum levels, MetS metabolic syndrome, WC waist circumference component, BP blood pressure component, Trig triglycerides component, HDL HDL cholesterol component, Glu glucose component Model 1: OR adjusted for gender and age; Model 2: OR adjusted for gender, age and body mass index

${ }^{\mathrm{a}} \mathrm{OR}(95 \% \mathrm{Cl})$ after adjustment for gender, age and $25(\mathrm{OH}) \mathrm{D}$ serum level: $1.013(1.001,1.025)$

$[3,15,16]$. In addition, according to a recent study, conducted in the city of Porto [17], which included 198 healthy participants, VitD deficiency or inadequacy was present in $48 \%$. In the winter period, these values reached $74 \%$.

Compared with other European [2] and worldwide [18] populations, the median $25(\mathrm{OH}) \mathrm{D}$ levels observed in this study were relatively low despite the favorable latitude. The high prevalence of pre-obesity and obesity may have contributed to these figures. Furthermore, VitD intake in the Portuguese population is relatively low [2].

Food fortification, VitD supplementation, sunlight exposure and UV protection habits may also be contributing factors to the differences observed across various countries. Several European countries have adopted measures at the national level to implement VitD supplementation and food fortification policies, but they are not harmonized across Europe [2]. In addition, dietary reference values for VitD intake have been a subject of debate in some countries. In Portugal, there is no legislation of food fortification and VitD supplementation (700-800 IU/day) in adults is only recommended for elderly populations ( $>65$ years) and subjects with osteoporosis, osteopenia or those with a major risk for osteoporosis [19].

\section{Functional hypoparathyroidism and the association between VitD and PTH}

Despite all of the complex interrelationships, no significant association between PTH and 25(OH)D was observed. This lack of association was previously reported [20] and may be partly explained by a "blunted PTH response" to VitD deficiency [13]. In fact, most participants with Vit D deficiency had a "blunted PTH response" (89.2\%). This response cannot be explained by the type of definition of hypovitaminosis D used (IOM) because according to its definition only participants with serum levels of $25(\mathrm{OH}) \mathrm{D}$ lower than $12 \mathrm{ng} / \mathrm{mL}$ and with normal serum PTH levels were considered. The "blunted PTH response" may correspond to a protective mechanism of bone mass, through the development of a functional hypoparathyroidism [13]. In addition to parathyroid dysfunction, other factors may contribute to the modification of the PTH response to low VitD levels [21-23], such as age, gender, BMI, kidney dysfunction, smoking, and serum calcium levels. Our results did not show a significant contribution of smoking, BMI and serum levels of calcium and creatinine to the "blunted PTH response", but we found positive associations with male gender and serum phosphorus levels and negative associations with age and serum levels of hs-CRP. A positive association was already described between PTH and hs-CRP serum levels [24].

In addition to the "blunted PTH response", other factors may have contributed to the lack of association between the PTH and 25(OH)D levels. The method of measurement strongly influences the VitD and PTH levels and may modify the relationship between them. Specifically, the chemiluminescent immunoassay may have underestimated the $25(\mathrm{OH}) \mathrm{D}$ measurements [25]. Regarding the third generation PTH assay, freezing may have contributed to reduced PTH levels [26]. However, previous studies on $25(\mathrm{OH}) \mathrm{D}$ showed great stability under freezing conditions [27]. Moreover, despite being a useful biomarker of VitD supply to target tissues, $25(\mathrm{OH}) \mathrm{D}$ may not be a good functional marker of the biologically active form, $1 \alpha, 25(\mathrm{OH})_{2} \mathrm{D}$, relative to PTH regulation. Finally, the upper reference value of normal serum PTH levels $(65 \mathrm{pg} / \mathrm{mL})$ that is usually used may not be appropriate as a cut-off point for the definition of high PTH levels $[13,21]$.

\section{VitD, PTH and MetS associations}

To the best of our knowledge, this is the first national study to evaluate $25(\mathrm{OH}) \mathrm{D}$ and PTH levels and their associations with MetS.

According to our data, MetS prevalence was high and increased with age, HOMA score, and insulin and hs-CRP levels (data not shown). These results are supported by previous studies [28]. 
Our study showed a significant positive association between PTH and age even after adjusting for sex. By contrast, no significant association between $25(\mathrm{OH}) \mathrm{D}$ and age was observed. According to a systematic review, PTH levels are positively correlated with age [23]. We also found a significant negative association between serum PTH levels and male gender [29].

Although higher PTH levels have been associated with increased risk of CVD [7], insulin resistance, blood pressure and obesity $[8,9]$ we did not find a significant association between MetS and PTH levels in the adjusted model. Others have found a positive association between PTH and MetS only among older men [8] and in morbidly obese individuals [9].

We found positive associations of PTH serum levels with BMI, WC and the WC component of MetS. As expected, the association with the WC component of MetS was lost after further adjustment for BMI. The link between PTH levels and increased body fat is supported by the evidence of increased body weight in primary hyperparathyroidism [30] and by the positive association with BMI [31]. This association may be even stronger in visceral adipose tissue [32], explaining the stronger correlation found with WC. PTH may increase adipose mass, especially in the visceral compartment, by increasing the influx of calcium into adipocytes.

The $25(\mathrm{OH})$ D levels showed a positive association with participation in physical exercise, which persisted after adjusting for sex and age. Regular outdoor physical activity is associated with higher levels of serum VitD [33], which can be partly explained by higher UV radiation exposure. Unfortunately, in this study, no data were available on the specific type of exercise practiced by the participants in our sample (indoor versus outdoor).

MetS was inversely associated with 25(OH)D levels even after adjusting for age and sex; however, the association was lost after further adjustment for BMI. A recent meta-analysis showed that the prevalence of MetS decreased at higher 25(OH)D concentrations [5].

In addition, the prevalence of hypovitaminosis $\mathrm{D}$ is generally increased in adults with CVD, namely in coronary heart disease and heart failure [34], and low 25(OH)D levels are associated with an increased risk of ischemic heart disease, myocardial infarction, and premature death [4]. Furthermore, results from a recent meta-analysis indicate a non-linear decrease in overall mortality as the 25(OH)D levels increase [35]. Low levels of vitamin $\mathrm{D}$ have been reported to be associated not only with obesity and insulin resistance but also with glucose intolerance, dyslipidemia, increased renin gene transcription, endothelial dysfunction, proliferation of vascular smooth muscle cells, thrombogenecity and inflammation [5]. However, low levels of vitamin D may be simply secondary to inflammation and other phenomena associated with obesity and insulin resistance.

We found a significant positive association of the $25(\mathrm{OH}) \mathrm{D}$ levels with BMI, but not with the WC and WC components of MetS. A bi-directional Mendelian randomization analysis [36] suggested a causal role of obesity for the risk of hypovitaminosis D. However, any causal effect of hypovitaminosis D in obesity is likely to be small. The possible mechanisms for the lower $25(\mathrm{OH}) \mathrm{D}$ concentrations in obesity [37] include: lower VitD dietary intake, reduced sunbathing habits due to a decreased willingness to expose the body, sedentary lifestyle and mobility limitations, decreased bioavailability due to sequestration in the adipose tissue and a volumetric dilution effect related to greater body weight.

A negative association of $25(\mathrm{OH}) \mathrm{D}$ with glycemia was observed, but not with the glycemic component of MetS. Several longitudinal cohort studies and a recent metaanalysis [38] demonstrated an inverse association between the 25(OH)D levels and increased risk of type 2 diabetes. VitD status can interfere with insulin secretion and insulin resistance. VitD stimulation of $\beta$-cell VDRs and local activation of the 1- $\alpha$-hydroxylase enzyme may contribute to the modulation of pancreatic $\beta$-cells calcium influx and insulin synthesis. VitD may also increase insulin sensitivity by increasing insulin receptor expression and by stimulating insulin-induced glucose transport.

A negative association was present between the $25(\mathrm{OH}) \mathrm{D}$ levels and triglycerides levels [39] and triglycerides component of MetS. Although the mechanisms are not clear, they may involve metabolism of triglycerides through modulation of the intracellular calcium content of adipocytes and hepatocytes. Hypovitaminosis D-related inflammation and insulin resistance may be other contributing factors.

Although no linear association was found between diastolic or systolic BP and the 25(OH)D levels (data not shown), the 25(OH)D levels showed a significant association with the BP component of MetS. According to the literature, VitD is inversely associated with BP [40], and several mechanisms have been proposed to be related to hypovitaminosis D and hypertension [41], including disruption of the negative endocrine regulation of renin gene expression, secondary hyperparathyroidism, and enhanced vascular tone through direct or indirect dysfunction of the endothelial and vascular smooth muscle cells.

Also, the associations observed between Mets and its individual components and PTH and $25(\mathrm{OH}) \mathrm{D}$ serum levels were generally weak. In fact, this was not surprising as the variables considered in those associations were continuous and therefore the calculated ORs represent the odds of an outcome occurring for an increased unit of PTH or $25(\mathrm{OH}) \mathrm{D}$ serum levels. 
Lastly, one must acknowledge some additional limitations of this study. Firstly, due to its cross-sectional nature, no causal relation can be inferred from the significant associations observed. Also, and finally, one could expect type I error in the evaluation of the crude associations due to multiple comparisons. Nevertheless, the authors do not expect that this could have occurred in the final model defined for this study, as the number of tested variables was in fact small.

\section{Conclusion}

The present study showed a high prevalence of hypovitaminosis D in a sample of the Portuguese population. Compared with other European and worldwide populations, our median level of $25(\mathrm{OH}) \mathrm{D}(13.8 \mathrm{ng} / \mathrm{mL})$ is relatively low. The prevalence of hypovitaminosis D was higher in participants with higher BMI and sedentary lifestyles.

The PTH levels showed a significant positive association with BMI, WC and the WC component of MetS, suggesting a possible role in the pathophysiology of obesity. The 25(OH)D levels were negatively associated with BMI, glucose and triglycerides levels as well as with MetS and its BP and triglycerides components, indicating that hypovitaminosis D may contribute to the pathophysiology of MetS.

Considering the low levels and inadequate intake of VitD, the frequency of overweight, and potentially insufficient solar exposure in the Portuguese population, it is crucial to develop national policies to increase awareness of the importance of VitD for health and to develop strategies for the identification of vitamin D deficiency, especially in at-risk groups.

\section{Abbreviations}

25(OH)D: 25-hydroxyvitamin D; BMl: Body mass index; Cl: Confidence interval; CVD: Cardiovascular disease; HC: Hip circumference; HOMA: Homeostatic model assessment; hs-CRP: High sensitivity C-reactive protein; Ht: Height: MetS: Metabolic syndrome; OR: Odds ratio; PTH: Parathyroid hormone; SD: Standard deviation; UV: Ultraviolet; VitD: Vitamin D; VitD3: Cholecalciferol; WC: Waist circumference; WHR: Waist-to-hip ratio; WHtR: Waist-to-height ratio

\section{Acknowledgements}

The authors would like to thank all PORMETS cohort-participants, logistic staff and scientists for their contribution to the study.

\section{Funding}

This work was supported by the Insulin Resistance Study Group of the Endocrinology, Diabetes and Metabolism Portuquese Society. Ana Cristina Santos holds a FCT Investigator contract IF/01060/2015.

\section{Availability of data and materials}

The datasets used and analysed during the current study are available from the corresponding author on reasonable request, once the study has been published.

\section{Authors' contributions}

$L R$, JTG and ACS were involved in the conception of the study. LR was involved in the statistical analysis. SM and DF were involved in the accomplishment of the laboratory exams. All authors were involved in drafting the manuscript, approving the final draft, and agree to be accountable for the work. All authors read and approved the final manuscript.

\section{Ethics approval and consent to participate}

All the Portuquese Regional Health Administrations, the Ethics Committee of the São João Hospital E.P.E. and the Portuguese Data Protection Authority, approved PORMETS. The Clinical Director of each health care center also provided authorization and all participants gave their written informed consent. The Ethics Committee of Centro Hospitalar São João (Porto, Portugal) approved the study in the 27th February 2007 and the authorization from the Portuguese Data Protection Authority is CNDP: 1053/2007.

\section{Consent for publication}

Not applicable.

\section{Competing interests}

The authors declare that they have no competing interests.

\section{Publisher's Note}

Springer Nature remains neutral with regard to jurisdictional claims in published maps and institutional affiliations.

\section{Author details}

${ }^{1}$ Grupo de Estudo da Insulino-Resistência, Sociedade Portuguesa de Endocrinologia, Diabetes e Metabolismo, Lisboa, Portugal. ${ }^{2}$ EPIUnit - Instituto de Saúde Pública da Universidade do Porto (ISPUP), Porto, Portugal. ${ }^{3}$ Serviço de Patologia Clínica, Centro Hospitalar de S. João, Porto, Portugal.

${ }^{4}$ Departamento de Biomedicina, Faculdade de Medicina, Universidade do Porto, Porto, Portugal. ${ }^{5}$ Departamento de Ciências da Saúde Pública e Forenses e Educação Médica, Faculdade de Medicina, Universidade do Porto, Porto, Portugal.

Received: 6 July 2017 Accepted: 12 November 2017

Published online: 17 November 2017

\section{References}

1. Verstuyf A, Verlinden L, Carmeliet G, Vitamin D. Metabolism, molecular mechanism of action, and pleiotropic effects. Physiol Rev. 2016;96(1):365-408.

2. Spiro A, Buttriss JL, Vitamin D. An overview of vitamin D status and intake in Europe. Nutr Bull. 2014:39:322-50.

3. Santos MJ, Fernandes V, Garcia FM, Vitamin D. Insufficiency in a hospital population: a photograph from the laboratory perspective. Acta Medica Port. 2015;28(6):726-34.

4. Brøndum-Jacobsen P, Benn M, Jensen GB, Nordestgaard BG. 25-Hydroxyvitamin $D$ levels and risk of ischemic heart disease, myocardial infarction, and early death. Population-based study and meta-analyses of 18 and 17 studies. Arterioscler Thromb Vasc Biol. 2012;32:2794-802.

5. SY J, Jeong HS, Kim DH, Blood Vitamin D. Status and metabolic syndrome in the general adult population: a dose-response meta-analysis. J Clin Endocrinol Metab. 2014;99:1053-63.

6. Fiuza M, Cortez-Dias N, Martins S, Belo A. Metabolic syndrome in Portugal: prevalence and implications for cardiovascular risk - results from the VALSIM study. Rev Port Cardiol. 2008;27:1495-529.

7. van Ballegooijen AJ, Reinders I, Visser M, Brouwer IA. Parathyroid hormone and cardiovascular disease events: a systematic review and meta-analysis of prospective studies. Am Heart J 2013;165:655-664.

8. Reis JP, von Mühlen D, Miller IIIER. Relation of 25-hydroxyvitamin D and parathyroid hormone levels with metabolic syndrome among US adults. Eur J Endocrinol. 2008;159(1):41-8.

9. Hjelmesaeth J, Hofsø D, Aasheim ET, Jenssen T, Moan J, Hager H, Røislien J, Bollerslev J. Parathyroid hormone, but not vitamin D, is associated with the metabolic syndrome in morbidly obese women and men: a cross-sectional study. Cardiovasc Diabetol. 2009;8:7. doi:10.1186/1475-2840-8-7.

10. Raposo L, Severo M, Barros H, Santos AC. The prevalence of the metabolic syndrome in Portugal: the PORMETS study. BMC Public Health. 2017;17:555. doi:10.1186/s12889-017-4471-9

11. WHO Expert Consultation. Appropriate body-mass index for Asian populations and its implications for policy and intervention strategies. Lancet. 2004; 363(9403):157-63.

12. Dietary Reference Intakes for Calcium and Vitamin D. Institute of Medicine (US) committee to review dietary reference intakes for vitamin D and calcium; Ross AC, Taylor CL, Yaktine AL, Del Valle HB, editors. Washington (DC): National Academies Press (US): 2011. The National Academies Collection: Reports funded by National Institutes of Health. 
13. Sahota O, Mundey MK, San P, Godber IM, Lawson N, Hosking DJ. The relationship between vitamin $\mathrm{D}$ and parathyroid hormone: calcium homeostasis, bone turnover, and bone mineral density in postmenopausal women with established osteoporosis. Bone. 2004;35:312-9.

14. Alberti KG, Eckel RH, Grundy SM, Zimmet PZ, Cleeman Jl, Donato KA, Fruchar JC, James WP, Loria CM, Smith SC Jr. Harmonizing the metabolic syndrome: a joint interim statement of the international diabetes federation task force on epidemiology and prevention; National Heart, Lung, and Blood Institute; American Heart Association; world heart federation; international atherosclerosis society; and International Association for the Study of obesity. Circulation. 2009; 120:1640-5.

15. Santiago T, Rebelo M, Porto J, Silva N, Vieira J, Nascimento Costa JM, Hypovitaminosis D. In patients admitted to an internal medicine Ward. Acta Medica Port. 2012;25(2):68-76.

16. Alves M, Bastos M, Leitão F, Marques GB, Ribeiro G, Carrilho F. Vitamin D importance of laboratory evaluation. Rev port Endocrinol Diabetes Metab. 2013;8(1):32-9.

17. Bettencourt A, Boleixa D, Reis J, Oliveira JC, Mendonça D, Costa PP, Silva BMD, Marinho A, Silva AMD. Serum 25-hydroxyvitamin D levels in a healthy population from the north of Portugal. J Steroid Biochem Mol Biol. 2016; doi:10.1016/j.jsbmb.2016.11.005.

18. Hilger J, Friedel A, Herr R, Rausch T, Roos F, Wahl DA, Pierroz DD, Weber P, Hoffmann KA. Systematic review of vitamin D status in populations worldwide. Br J Nutr. 2014;111(1):23-45.

19. Direção-Geral da Saúde. Orientação técnica sobre suplementação de cálcio e vitamina D em pessoas idosas. Circular Informativa $n^{\circ}$ 13/DSCS/DPCD/ DSQC de 01/04/2008 (directorate-general of health. Technical guidance on calcium and vitamin D supplementation in older people. Information circular no.13/DSCS/DPCD/DSQC, 1th of April, 2008). https://www.dgs.pt/ directrizes-da-dgs/orientacoes-e-circulares-informativas.aspx?v=bd49e2a62a97-4d83-a400-f56e62144500\&cachecontrol=1510749437896. Acessed 15 Nov 2017.

20. Kilicarslan A, Aslan AC, Gezgen G. The role of vitamin D deficiency in parathyroid hormone levels. Turk J Med Sci. 2013:43(3):368-72.

21. Adami S, Viapiana O, Gatti D, Idolazzi L, Rossini M. Relationship between serum parathyroid hormone, vitamin D sufficiency, age, and calcium intake. Bone. 2008;42(2):267-70.

22. Gunnarsson ö, Indridason S, Franzson L, Sigurdsson G. Factors associated with elevated or blunted PTH response in vitamin D insufficient adults. J Intern Med. 2009;265:488-95.

23. Björkman M, Sorva A, Tilvis R. Responses of parathyroid hormone to vitamin D supplementation: a systematic review of clinical trials. Arch Gerontol Geriatr. 2009:48(2):160-6.

24. Cheng SP, Liu CL, Liu TP, Hsu YC, Lee JJ. Association between parathyroid hormone levels and inflammatory markers among US adults. Mediat Inflamm. 2014;2014:709024. doi:10.1155/2014/709024.

25. Wallace AM, Gibson S, de la Hunty A, Lambert-Allardt C, Ashwell M. Measurement of 25-hydroxyvitamin D in the clinical laboratory: current procedures, performance characteristics and limitations. Steroids. 2010; 75(7):477-88. doi:10.1016/j.steroids.2010.02.012.

26. Hanon EA, Sturgeon CM, Lamb EJ. Sampling and storage conditions influencing the measurement of parathyroid hormone in blood samples: a systematic review. Clin Chem Lab Med. 2013;51(10):1925-41.

27. Ocke MC, Schrijver J, Obermann-de Boer GL, Bloemberg BP, Haenen GR, Kromhout D. Stability of blood (pro)vitamins during four years of storage at -20 degrees C: consequences for epidemiologic research. J Clin Epidemiol. 1995;48:1077-85.

28. Kaur J. A comprehensive review on metabolic syndrome. Cardiol Res Pract. 2014:2014:943162. doi:10.1155/2014/943162.

29. Paik JM, Farwell WR, Taylor EN. Demographic, dietary, and serum factors and parathyroid hormone in the National Health and nutrition examination survey. Osteoporos Int. 2012;23(6):1727-36.

30. Bolland MJ, Grey AB, Gamble GD, Reid IR. Association between primary hyperparathyroidism and increased body weight: a meta-analysis. J Clin Endocrinol Metab. 2005;90:1525-30.

31. Guasch A, Bulló M, Rabassa A, Bonada A, Del Castillo D, Sabench F, Salas-Salvadó J. Plasma vitamin $D$ and parathormone are associated with obesity and atherogenic dyslipidemia: a cross-sectional study. Cardiovasc Diabetol. 2012;11:149. doi:10.1186/ 1475-2840-11-149.
32. George JA, Norris SA, Toman M, Snyman T, Crowther NJ. Visceral adiposity is a predictor of parathyroid hormone levels in healthy adults. J Endocrinol Investig. 2016;39:447-53.

33. Scragg R, Camargo CA Jr. Frequency of leisure-time physical activity and serum 25-hydroxyvitamin D levels in the US population: results from the third National Health and nutrition examination survey. Am J Epidemiol. 2008;168(6):577-86.

34. Kim DH, Sabour S, Sagar UN, Adams S, Whellan DJ. Prevalence of hypovitaminosis $D$ in cardiovascular diseases (from the National Health and nutrition examination survey 2001 to 2004). Am J Cardiol. 2008;102(11):1540-4.

35. Zittermann A, lodice S, Pilz S, Grant WB, Bagnardi V, Gandini S, Vitamin D. Deficiency and mortality risk in the general population: a meta-analysis of prospective cohort studies. Am J Clin Nutr. 2012;95:91-100.

36. Vimaleswaran KS, Berry DJ, Lu C, Tikkanen E, Pilz S, Hiraki LT, et al. Causal relationship between obesity and vitamin D status: bi-directional Mendelian randomization analysis of multiple cohorts. PLoS Med. 2013;10(2):e1001383. doi:10.1371/journal.pmed.1001383.

37. Vanlint S. Vitamin D and Obesity. Nutrients. 2013;5:949-56.

38. Afzal S, Bojesen SE, Nordestgaard BG. Low 25-Hydroxyvitamin D and risk of type 2 diabetes: a prospective cohort study and metaanalysis. Clin Chem. 2013;59(2):381-91.

39. Jorde R, Figenschau Y, Hutchinson M, Emaus N, Grimnes G. High serum 25hydroxyvitamin $\mathrm{D}$ concentrations are associated with a favorable serum lipid profile. Eur J Clin Nutr. 2010;64(12):1457-64.

40. Burgaz A, Orsini N, Larsson SC, Wolk A. Blood 25- hydroxyvitamin D concentration and hypertension: a meta-analysis. J Hypertens. 2011;29: 636-45.

41. Chen S, Sun Y, Agrawal DK. Vitamin D deficiency and essential hypertension. J Am Soc Hypertens. 2015;9(11):885-901.

\section{Submit your next manuscript to BioMed Central and we will help you at every step:}

- We accept pre-submission inquiries

- Our selector tool helps you to find the most relevant journal

- We provide round the clock customer support

- Convenient online submission

- Thorough peer review

- Inclusion in PubMed and all major indexing services

- Maximum visibility for your research

Submit your manuscript at www.biomedcentral.com/submit 